UDC 536.46.:532.517.4

\author{
${ }^{1}$ A.S. Askarova, ${ }^{1}$ S.A. Bolegenova, ${ }^{1}$ V.Ju. Maximov, ${ }^{1}$ Z.Kh. Gabitova ${ }^{*}$, \\ ${ }^{2} \mathrm{R}$. Leithner, ${ }^{2} \mathrm{H}$. Müller, ${ }^{2}$ Ye. Heierle \\ ${ }^{1}$ Department of physics and technology, al-Farabi Kazakh National University, \\ Almaty, Kazakhstan \\ ${ }^{2}$ Institut für Wärme- und Brennstofftechnik, TU Braunschweig, Germany \\ *e-mail: gabitova.zarina@mail.ru

\section{Numerical simulation of high-ash coal combustion with different moisture content at aksu thermal power plant}

\begin{abstract}
The main purpose of research is to predict the influence of different water content in coal on overall furnace operation and formation of combustion products. Numerical experiments was carried out on the basis of three-dimensional equations of convective heat and mass transfer, taking into account the heat propagation, heat radiation, chemical reactions and multiphase structure of the medium. This paper presents the results of numerical modeling of high-ash Ekibastuz coal burning in combustion chamber of Kazakhstan Power Plant. Increase of water content in coal leads to reduce the amount of harmful emissions and decrease the average temperature in the combustion chamber.
\end{abstract}

Key words: coal combustion, coal moisture, heat and mass transfer, furnace, numerical methods.

\section{Introduction}

The power system of Kazakhstan is presented mostly by thermal power stations. Thermal power stations produce more than $70 \%$ of total amount of the electric power. The main source of energy generated by thermal power plants is coal combustion. However, Kazakhstan coal is lowgrade high ash. Burning this coal leads to combustion instability, slagging of heating surfaces and other problems. Therefore, it is necessary to investigate the influence of various characteristics on the combustion processes.

Fuel moisture is one of the most important characteristics of the fuel. Burning coal with high moisture content is accompanied by a decrease in the intensity of the heat and mass transfer processes as part of the heat goes to the coal drying.

The simulations of the furnaces was carried out with FLOREAN - a 3D-Finite Volume simulation tool developed at the Institut für Wärme - und Brennst of ftechnik based on the numerical solution of the Reynolds averaged balance equations for mass, species, energy and momentum [1]. The computer simulation is performed for furnace chamber of Kazakhstan Power Plants. Low-rank Ekibastuz bituminous coal is incinerated at the boiler PK39 with a steam capacity of $475 \mathrm{t} / \mathrm{h}$. The boiler is installed in Aksu Thermal Power Plant. The cross section of furnace is $10,8 \mathrm{~m} \mathrm{x} 7,8 \mathrm{~m}$ with a height of $30 \mathrm{~m}$. Twelve swirl burners are placed in two layers. Three burners in each layer are on the front and rear wall of the furnace.

Table 1 - Ekibastuz coal composition

\begin{tabular}{|c|c|c|c|c|c|c|}
\hline Water & Ash & C (daf) & H (daf) & O (daf) & N (daf) & S (daf) \\
\hline 7,0 & 40,9 & 78,9 & 5,4 & 12,7 & 1,5 & 1,5 \\
\hline
\end{tabular}




\section{Results of numerical experiments}

Figure 1 shows temperature distribution along the height of the combustion chamber for burning of coal with different water content in initial air-fuel stream. The experimental data $[2,3]$ are given here for coal burning with $7 \%$ moisture. We can see differences of calculated and experimental values of temperature in the region of ignition and extinction.
It's seen that the zone of maximum temperatures is concentrated in the center of the fire-chamber on the level of the burners. Curve minimums caused by low temperature $\left(150^{\circ} \mathrm{C}\right)$ of fuel mixture supplied in the chamber space through the burners. We can see that higher water content causes decrease in temperature in this section of combustion chamber. At the outlet of the furnace temperature aligns and reaches a value of about $1200^{\circ} \mathrm{C}$.

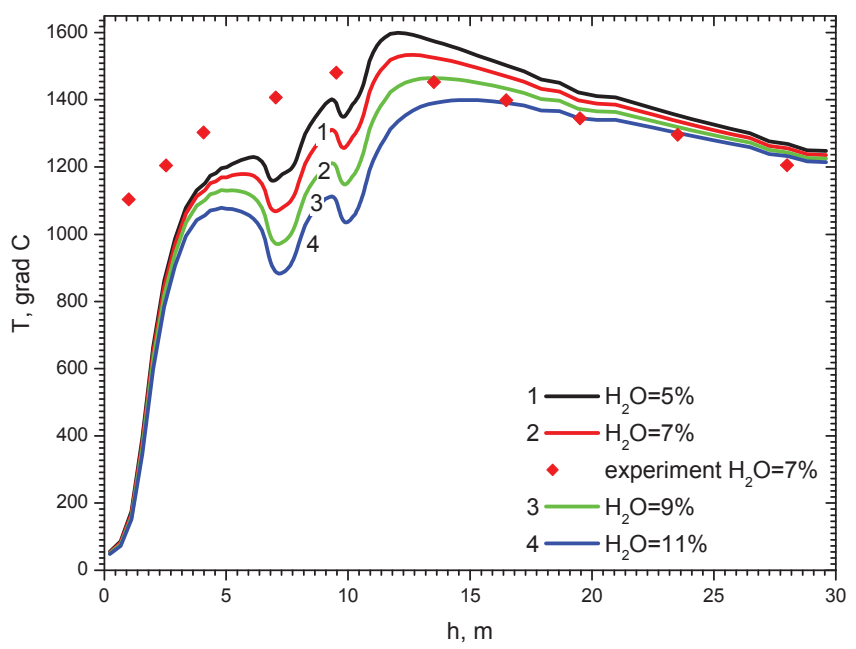

Figure 1 - Temperature distribution along the chamber height for coal burning with different water content

Figures 2-5 show picture of coal combustion products $\left(\mathrm{H}_{2} \mathrm{O}, \mathrm{CO}, \mathrm{CO}_{2}, \mathrm{NO}\right)$ fields along the chamber height with different water content.
Distribution of water vapor is on the figure 2 . We can see that the $\mathrm{H}_{2} \mathrm{O}$ concentration grows as water content in coal increases.

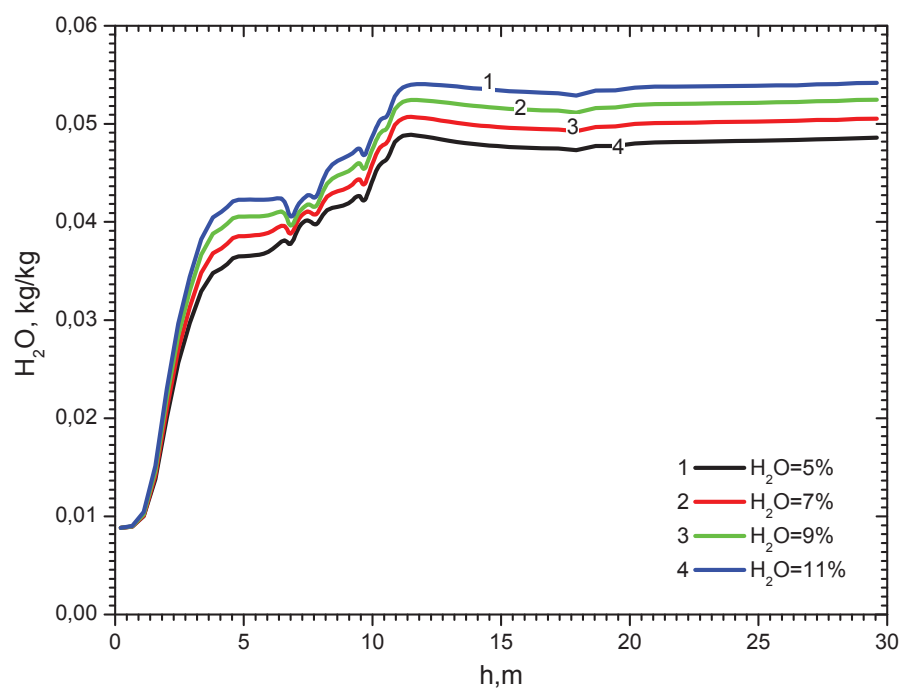

Figure $2-\mathrm{H}_{2} \mathrm{O}$ concentration distribution along the chamber height for coal burning with different water content 
Figures 3-4 present distribution of carbon oxides in furnace chamber. We can notice differences in the mechanisms of carbon oxides formation. $\mathrm{CO}$ concentration reaches maximum value in the central part of combustion chamber, where burning processes are intensive. To the outlet of furnace concentration of carbon monoxide decreases. It is connected with oxidize reactions of $\mathrm{CO}$ to $\mathrm{CO}_{2}$.

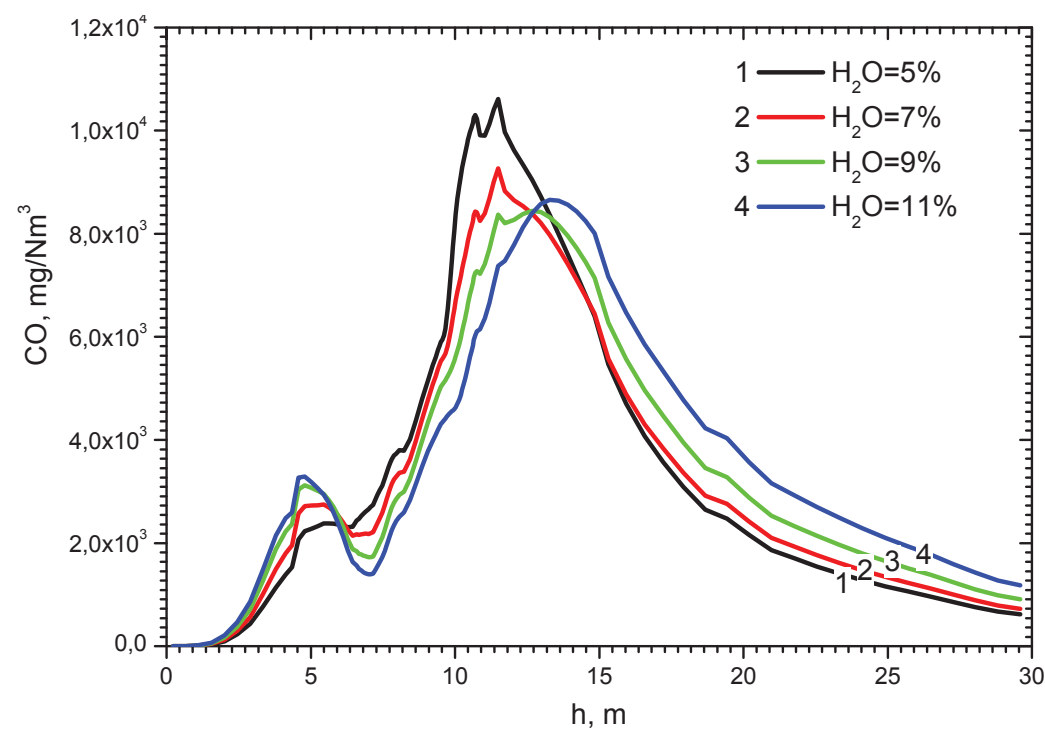

Figure 3 - COconcentration distribution along the chamber height for coal burning with different water content

The maximum difference of calculation and experiment (fig. 4) is seen in the region of ignition and extinction of flying matters. The main reason for this is that there is a determination of the gas burning rate by one stage model of piroliz where the set of kinetic constants for all the entire temperature range are used. The figures show that the regions with maximum difference coincide with regions having high concentrations of carbon oxide.

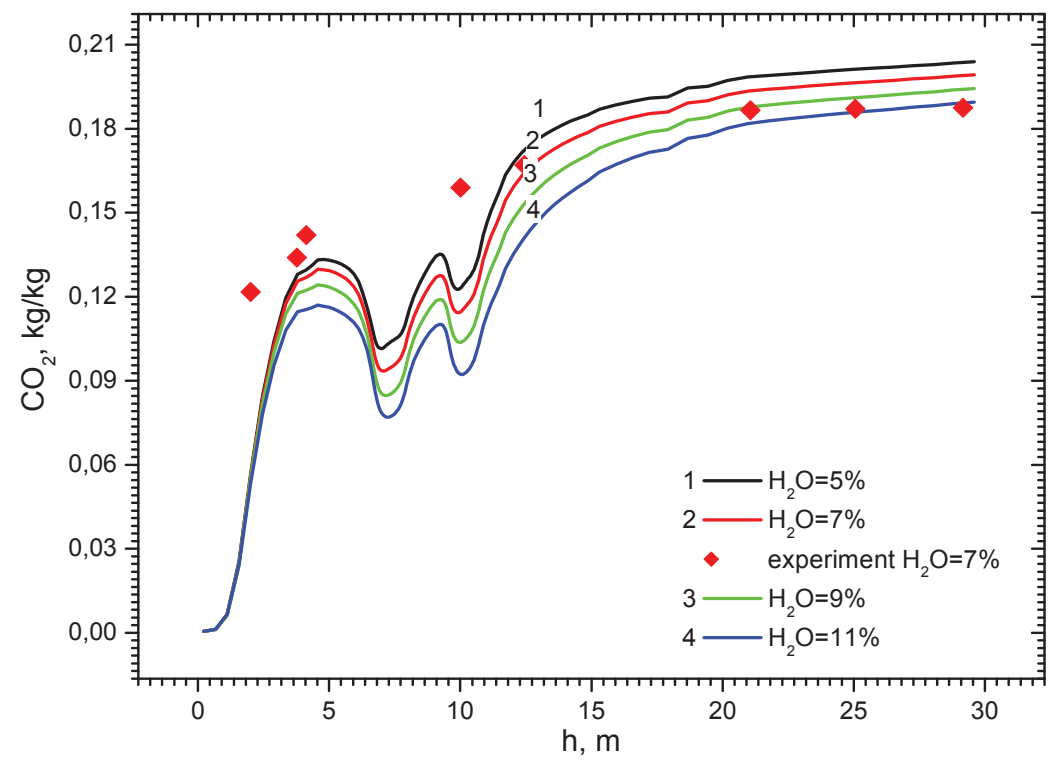

Figure $4-\mathrm{CO}_{2}$ concentration distribution along the chamber height for coal burning with different water content 
One of the most pollutant emissions is nitrogen oxides. About $40 \%$ of $\mathrm{NO}_{\mathrm{x}}$ releases from industry. Figure 5 shows concentration distribution along the chamber height for coal burning with different water content. Increasing water content reduces $\mathrm{NO}$ emissions in the level burners. Although at the outlet of the furnace NO concentration aligns and reaches about $500 \mathrm{mg} / \mathrm{Nm}^{3}$.

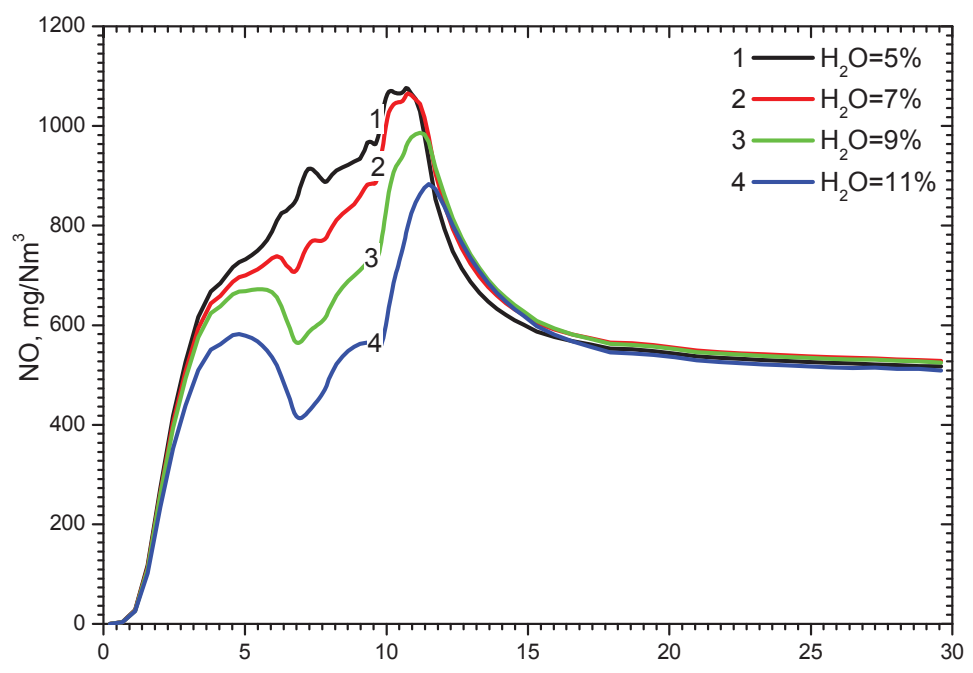

Figure 5 - NOconcentration distribution along the chamber height for coal burning with different water content

\section{Conclusions}

In present paper computational fluid dynamics simulation tool was used to numerically simulate and analyze low-rank coal combustion and flow properties of industrial furnaces of Kazakhstan Power Plants. The simulations of the furnaces of steam generator PK39 of AksuTPP have been carried to predict the influence of different water content in coal on overall furnace operation and formation of combustion products. The results of research shows that:

- higher water content causes decrease in temperature in the burning level section of combustion chamber;

- the main formation regions of gases in the coal dust torch take place at the level of burners in the central part of the furnace volume;

- water content in the total gas mixture at the outlet consequently increase with water content in coal.

- at the outlet of furnace chamber decreasing coal moisture decrease $\mathrm{CO}$ concentration and increase $\mathrm{CO}_{2}$ concentration.
- difference in NO formation for studied coal content is seen mostly in the region of burners location. At the furnace outlet the difference in NO concentrations is slight appearing.

The distribution character of all concentrations, listed in this paper is modeled sufficiently and it agrees with the experimental data.

\section{References}

1. Leithner R., Müller H. Second M.I.T. Conference on Computational Fluid and Solid Mechanics. - Cambridge, 2003. - P.988-991.

2. Alijarov B.K. Osvoenie szhiganijaj ekibastuzskogo uglja na teplovyh jelektrostancijah. - Almaty: Ghylymordasy, 1996. - 272 p.

3. Alijarov B.K., Alijarova M.B. Szhiganie kazahstanskih uglej na TJeSina krupnyh kotl'nyh. Almaty: Ghylymordasy, 2012. - 130 p. 